\title{
A valoração de recursos que geram vantagens competitivas sustentáveis
}

\author{
The valuation of resources that generate sustainable competitive advantage
}

Carlos Marcelo Lauretti ${ }^{[a]}$, José Matias Filho ${ }^{[b]}$, Leonardo Fernando Cruz Basso ${ }^{[c]}$

[a] Doutorando em Administração pela Universidade Presbiteriana Mackenzie, São Paulo, SP - Brasil, e-mail: clauretti@gmail.com

[b] Doutorando em Administração pela Universidade Presbiteriana Mackenzie, São Paulo, SP - Brasil, e-mail: josematiasfilho@yahoo.com.br

[c] Doutor pela New School for Social Research, professor da Universidade Presbiteriana Mackenzie, São Paulo, SP - Brasil, e-mail: leonardofernandbasso@terra.com.br

\section{Resumo}

Este ensaio teórico busca unir a abordagem de finanças corporativas para valoração dos ativos intangíveis aos estudos de estratégia que argumentam que são os recursos intangíveis idiossincráticos das empresas que as levam a deter vantagens competitivas sustentáveis. A literatura acadêmica de finanças corporativas costuma atribuir valor aos ativos intangíveis das empresas como sendo a diferença entre o valor de mercado (marketvalue) e o seu valor contábil (book value). Pesquisadores desta área de conhecimento observaram que existe uma relação positiva entre o índice market-to-book e as perspectivas de desempenho financeiro das empresas. Por outro lado, a abordagem que ficou conhecida em estudos de estratégia como a Visão Baseada em Recursos RBV (Resource-BasedView) - destaca a importância de a empresa deter recursos valiosos, raros, não completamente imitáveis ou substituíveis como fontes de vantagens competitivas sustentáveis. Este estudo busca mostrar que estes recursos estratégicos podem ser mensurados através da abordagem de finanças corporativas para os ativos intangíveis que não são reconhecidos em seus demonstrativos patrimoniais contábeis, porém estão refletidos em seu valor de mercado.

Palavras-chave: Ativos intangíveis. Visão baseada em recursos. Price-to-book. Book-to-market.

\begin{abstract}
This theoretical essay aims to establish the connectionbetween the corporate finance valuation of intangible assets approach and strategic studies that argue that idiosyncratic intangible assets of companies that lead them to hold sustainable competitive advantages. Corporate finance academic literature typically assigns value to intangible assets of companies as the difference between the market value and its book value. Researchers of this area of knowledge observed that there is a positive relationship between the market-to-book index and perspectivesof financial performance. On the other hand, the approach that became known in studies of strategy as Resource-Based View
\end{abstract}


(RBV) highlights the importance of a company hold valuable, rare, neither perfectly imitable nor substitutable resources asorigin of sustainable competitive advantages. This study aims to show that these strategic resources can be measured through the corporate finance approach to not recognized intangible assets in accounting reports, but that compound their market value.

Keywords: Intangible assets. Resource-based view. Price-to-book. Book-to-market.

\section{Introdução}

Tendo como principal missão o aumento da riqueza em longo prazo dos acionistas e investidores externos, os administradores de empresas têm uma preocupação constante de desenvolver formas de cumprir esta missão por meios produtivos, comerciais, financeiros ou estratégicos. Neste contexto, a busca da Vantagem Competitiva Sustentável (VCS) apresenta-se como uma das mais significativas formas de se obter e sustentar a geração de tal riqueza.

A comunidade acadêmica financeira vem ao longo do tempo buscando modelos de mensurar essa riqueza, a fim de disponibilizar às empresas e à sociedade em geral meios e ferramentas para quantificar e avaliar este fator de criação de valor. Além disso, busca mensurar o quanto as empresas estão contribuindo com a adição de valor à sociedade como um todo. A discussão sobre os denominados ativos intangíveis das empresas, em sua grande parte não apresentada nos demonstrativos financeiros, faz parte desse conjunto de preocupações dos pesquisadores de finanças corporativas. Vem sendo objeto de pesquisa no meio acadêmico e empresarial, em termos de sua identificação, ou mesmo da valoração desses ativos, com a finalidade de compor o verdadeiro valor da firma.

Por outro lado, na área de pesquisa em estratégia, outra corrente busca identificar os chamados recursos estratégicos da empresa, fontes de vantagem competitiva sustentável, um dos principais campos de estudo da área.

Entendemos que é possível estabelecer uma ligação entre os denominados ativos intangíveis tratados em finanças, e os recursos estratégicos tratados no âmbito da área de estratégia, utilizando os métodos de mensuração dos ativos intangíveis presentes em finanças corporativas como uma proxy para valoração dos recursos estratégicos não físicos, os chamados recursos humanos, organizacionais e relacionais.

A valoração das firmas, e de forma implícita, a correta atribuição e percepção de valor aos seus ativos intangíveis pelo mercado ou por aqueles que colocam seus recursos em investimentos nas empresas, é fator determinante para o desenvolvimento de estratégias, ou em outras palavras, das escolhas estratégicas para novos investimentos em ativos que criam valor. É, portanto, fundamental que as visões estratégicas e de finanças possam estar alinhadas, objetivo central deste estudo que busca alinhar as duas perspectivas sobre este mesmo tema.

\section{Problema de pesquisa}

Neste estudo, são abordadas as relações entre as teorias de estratégia fundamentadas na ResourceBasedView (RBV) e as teorias de finanças corporativas de atribuição de valor aos ativos intangíveis das firmas. É recuperada a literatura acadêmica que destaca o desempenho financeiro superior das empresas que detêm recursos valiosos, raros, inimitáveis e insubstituíveis. Estes recursos normalmente são representados por ativos gerados pelo conhecimento, cultura, valores, reputação, tecnologia, relações entre clientes e fornecedores, propriedade intelectual e outros, e que têm na intangibilidade a sua característica principal.

Em estudos de finanças corporativas é um tema recorrente a análise da relação positiva da razão entre o valor de mercado e o valor contábil das empresas, conhecido como Price-to-Book (P/B), e o seu desempenho financeiro. $\mathrm{Ou}$, de forma inversa, é possível constatar uma relação negativa entre o índice Book-to-Market (B/M) e o desempenho financeiro.

Este estudo busca mostrar que a diferença entre o valor de mercado e o valor contábil de uma empresa tem origem nos seus ativos intangíveis, pois estes preponderantemente não são contabilizados ou é mesmo impossível contabilizá-los. Busca-se mostrar que é possível associar estes ativos intangíveis ao que a literatura de recursos considera fatores geradores de vantagens competitivas sustentáveis. 
Implicações práticas

Este estudo procura mostrar que as abordagens dos ativos intangíveis financeiros e gestão de recursos estratégicos são complementares, e as explicações sobre retornos no mercado de capitais de firmas com diferentes graus de intangibilidade não poderiam ser explicados satisfatoriamente somente por fatores baseados em risco. Estudos como este visam contribuir para a melhor compreensão dos retornos obtidos pelos investidores e que influenciam fortemente as decisões estratégicas de alocação de recursos em ativos, quer sejam tangíveis ou intangíveis. A correta avaliação do mercado a respeito dos ativos intangíveis é uma questão relevante no planejamento estratégico porque os recursos financeiros necessários para o desenvolvimento de estratégias de crescimento têm origem na percepção de criação de valor pelos investidores, e que também assumem o papel de retroalimentadores do processo.

\section{Originalidade}

São conhecidos estudos de estratégia que relacionam intangibilidade ao retorno fundamental (contábil) futuro e também os estudos em finanças que associam altos retornos de mercado com altos índices B/M (baixa intangibilidade). As explicações dominantes nas últimas décadas em finanças corporativas apontam para o B/M como uma variável substituta (proxy) para fatores de risco percebidos pelo mercado mas não presentes nos modelos tradicionais de apreçamento de ativos. Empresas com altos índices B/M são consideradas em finanças como empresas de alto risco e, portanto, deveriam oferecer um retorno maior para os seus investidores. Ao contrário, empresas com baixos índices B/M, são tidas como empresas de alto desempenho e, portanto, de baixo risco. Com isso, oferecem menor retorno para seus investidores. Ao serem colocadas lado a lado as abordagens de finanças corporativas e de recursos estratégicos para a origem da diferença entre o valor de mercado e valor contábil, verifica-se que as explicações dominantes em finanças corporativas para estas observações não são satisfatórias e desconsideram aspectos importantes dos direcionadores de valor dos ativos intangíveis. Estudos que contraponham as duas abordagens ainda não receberam destaque nos meios acadêmicos.

\section{Estrutura do estudo}

Este estudo é caracterizado como um ensaio teórico no qual se procura mostrar através da revisão da literatura acadêmica que os métodos propostos pelos pesquisadores de finanças corporativas para valoração dos ativos intangíveis podem ser utilizados para atribuir valor aos recursos estratégicos que levam as empresas a possuir vantagens competitivas sustentáveis. Como um ensaio teórico, procura expor de forma lógica e reflexiva a argumentação, amparado-a por autores reconhecidos nestas áreas de conhecimento, porém com algum nível de interpretação e julgamento pessoal de seus autores. Neste sentido, os autores se dão maior liberdade para defender essas posições sem necessariamente precisarem se apoiar no rigoroso e objetivo aparato de documentação empírica e bibliográfica.

Neste primeiro item do estudo foi feita a introdução ao assunto e abordou-se suas implicações práticas e originalidade do tema. A seguir apresentaremos o referencial teórico utilizado para fundamentar as questões abordadas. Primeiramente, abordaremos os recursos estratégicos sob uma Visão Baseada em Recursos (RBV) e, em seguida, serão introduzidas questões relacionadas ao valor dos ativos intangíveis sob uma perspectiva de finanças corporativas. Também traremos à discussão a influência da percepção do mercado quanto ao risco da intangibilidade no valor da empresa. Ao final serão feitas considerações adicionais sobre os recursos estratégicos e os ativos intangíveis, procurando demonstrar sua relação.

\section{Referencial teórico}

0 referencial teórico baseia-se em literatura mais recente que aborda os temas de estratégia e que tenha como tema central a visão baseada em recursos. Por outro lado, recorre-se à literatura que caracteriza e valora os ativos intangíveis. A partir destas literaturas, fez-se uma busca pelos textos dos autores mais citados, e dessa forma foram encontrados autores como Porter (1980), Porter (1985), Penrose (1959), Wernerfelt (1984), Barney (1986), Barney (1991), Peteraf (1993), Prahalad e Hamel (1994), além de vários outros. No âmbito da literatura de ativos intangíveis, destacam-se Sveiby (1998), Lev (2001), Stewart (2001), Lev e Daum (2004). Ainda são citados alguns autores acadêmicos de finanças 
corporativas para fundamentar questões como, por exemplo, a composição do valor da empresa.

A busca da vantagem competitiva sustentável e a visão baseada em recursos - RBV

No âmbito da VCS, encontram-se estudos que tratam da definição e identificação dos recursos considerados estratégicos das empresas, levando a comunidade acadêmica a propor diversas abordagens sobre o tema. Porter (1980) e Porter (1985) propõe uma abordagem baseada em aspectos da indústria (setor de atividade, mercado de atuação), apresentando um modelo que ficou conhecido como "modelo das cinco forças de mercado", e que determinaria onde as empresas deveriam concentrar seus esforços para obter VCS. Essas forças de mercado seriam: poder de barganha de fornecedores, poder de barganha dos compradores, barreiras à entrada de novos competidores, análise dos concorrentes atuais e novos concorrentes/substitutos. $\mathrm{O}$ autor defende que estas estratégias deveriam se basear na diferenciação e liderança geral em custos, culminando em produtos diferenciados na sua forma e preços. Esta visão foi considerada como claramente voltada para o ambiente externo das empresas, visando seus mercados de atuação.

Outra corrente surgida da questão da busca de VCS foi a que ficou conhecida nos meios acadêmicos como RBV, sigla do original em inglês para ResourceBasedView, ou Visão Baseada em Recursos, e que teve como autores seminais Penrose (1959), Wernerfelt (1984), Barney (1986), Barney (1991), Peteraf (1993), entre outros.

Esta visão é voltada aos processos e dinâmicas internas das empresas. Aborda como o conjunto de recursos por elas utilizados poderia levar à obtenção de VCS. Penrose (1959, p. 24) afirma que as empresas são "uma coleção de recursos produtivos", divididos basicamente em recursos físicos (planta, equipamentos, recursos naturais, matérias-primas, etc.) e humanos (técnicas de produção, administrativas, financeiras, legais e gerenciamento); estes últimos claramente intangíveis. Já Wernerfelt (1984), responsável inclusive por cunhar o termo RBV, coloca os recursos da empresa como fazendo parte de uma matriz Recursos/Produtos, onde a ideia geral seria aplicar o potencial de um recurso específico em um único mercado (produto), expandindo posteriormente, fazendo dessa forma um paralelo com a questão das barreiras de entrada, proposta por Porter (1980). Barney (1986) propõe uma discussão da maneira como as empresas deveriam provocar imperfeições na competição do mercado a fim de obter rendas maiores que o normal, utilizando para tanto recursos estratégicos, únicos, controlados pelas mesmas. Em Barney (1991), a visão do autor de busca por VCS se baseou no conceito de recursos estratégicos como fonte de tal vantagem, onde esses recursos precisavam ser: valiosos, raros, não completamente imitáveis e insubstituíveis, para que pudessem gerar vantagem competitiva sustentável. Na sua visão, esses recursos seriam compostos de: recursos físicos, humanos e organizacionais, sendo os dois últimos tipos de natureza intangível. Já Peteraf (1993) define que as empresas, na busca por VCS, precisam ser heterogêneas em termos de seus recursos e capabilities internas. A autora sugere que heterogeneidade pode aparecer através de fatores de produção superiores demonstrados pelas empresas frente a uma limitação de recursos, provocando desta forma custos médios menores que as demais empresas componentes da indústria. A autora afirma que a existência de recursos superiores nas empresas resultaria na obtenção de novas rendas.

Destaca Sullivan Junior (2000) que a visão do empreendimento é uma das mais importantes peças dos ativos intangíveis. Afirma que a visão é planejada pela estratégia e executada por valores que direcionam a decisão para investimentos em ativos futuros, mantendo os investimentos correntes ou descartando-os. A estratégia é utilizada para desenvolver e sustentar vantagens competitivas correntes e futuras.

Vantagens competitivas dependem da eficácia do comando e acesso à eficiente utilização dos recursos e conhecimentos da firma (PORTER, 1980; PRAHALAD; HAMEL, 1994; BARNEY, 2001). Isto oferece ao negócio a capacidade de desenvolver vantagens em custo e diferenciação. A estratégia inclui todas as áreas, como as dos mercados, fornecedores, recursos humanos, vantagens competitivas, posicionamento, fatores críticos de sucesso e cadeia de valor (PORTER, 1980).

O papel dos recursos intangíveis na estratégia é um tema recorrente na literatura acadêmica. Hall (1993), por exemplo, analisa a relevância das fontes intangíveis de vantagens competitivas sustentáveis, argumentando que ela resulta da posse de capabilities heterogêneas. Diz que capabilities regulatórias 
e posicionais estão relacionadas com ativos intangíveis e capabilities funcionais e culturais estão relacionadas com competências. Afirma que um modelo interligando recursos intangíveis a capabilities pode ser utilizado como fundamento para se identificar as contribuições de diferentes recursos intangíveis para a vantagem competitiva.

Amit e Schoemaker (1993) destacam a relevância dos ativos estratégicos, um constructo situado no nível da firma, que se refere ao conjunto de recursos e capabilities desenvolvidos pela gestão como a base para criar e proteger as vantagens competitivas da firma. Argumentam que não é uma questão simples a decisão estratégica de identificar, desenvolver e disponibilizar o conjunto adequado de ativos estratégicos. Devido à incerteza, complexidade e conflito, tanto interno como externo à firma, distintas firmas empregam diferentes ativos estratégicos, sem que qualquer dos conjuntos seja comprovadamente ótimo ou facilmente imitável. Dizem que, quanto muito, a gestão da firma pode desenvolver soluções heurísticas que transpassam entre numerosos vieses cognitivos e afetivos, característicos dos seres humanos e organizações. Destacam que neste contexto o papel dos conflitos intraorganizacionais e a inércia podem ser identificados como barreiras importantes para impor mudanças ao conjunto de ativos estratégicos das firmas.

\section{Ativos intangíveis como adicionadores}

de valor às empresas

Do ponto de vista financeiro, Lev (2001) define Ativo Intangível como um direito a benefícios futuros que não possui corpo físico ou financeiro (ações ou títulos de dívida). Brealey e Myers (2003) destacam que as empresas investem em uma variedade de ativos reais, que incluem ativos tangíveis, como fábricas e máquinas, e também em ativos intangíveis, como contratos de gestão, patentes, na organização, conhecimento, pesquisa, etc. 0 objetivo da decisão de investimento, ou de orçamento de capital, é gerar ativos reais que tenham mais valor do que custam, ou seja, gerem valor adicional. Sveiby (1998) define ativos intangíveis como sendo aqueles que não estão contabilizados no balanço patrimonial das empresas. Por trás desta abordagem está a constatação de que, em geral, o valor de mercado das firmas suplanta seu valor contábil. Como as empresas não negociam rotineiramente seus ativos intangíveis, não se pode valorá-los por meio dos preços praticados nas transações empresariais. Assim, o valor dos ativos intangíveis só aparece de forma indireta no mercado de capitais ou quando uma empresa troca de proprietário.

Alguns autores, como Stewart (2001), sugerem que o valor de mercado é a soma dos valores dos ativos tangíveis e intangíveis das empresas. Quando se trata do valor econômico de uma empresa, dois conceitos devem ser abordados: o valor intrínseco e o valor de mercado. 0 valor intrínseco de uma empresa, segundo Sharpe, Alexander e Bailey (1995), é equivalente ao fluxo de caixa esperado descontado por uma taxa apropriada ao seu risco. Sob a Hipótese de Mercados Eficientes (HME, que veremos mais à frente), o valor de mercado das empresas representa o seu valor intrínseco. 0 valor dos ativos tangíveis de uma firma é formado por seus ativos imobilizados e pelo capital de giro líquido. Para os ativos tangíveis, há um mercado ativo para eles e, portanto, o seu valor de mercado representaria seu valor intrínseco. É por isso que podem ser reconhecidos facilmente no valor contábil da empresa. Seguindo este raciocínio, podemos admitir que o valor dos ativos intangíveis pode ser obtido subtraindo-se do valor de mercado da empresa o valor contábil do seu ativo imobilizado e capital de giro líquido.

Lev e Daum (2004) afirmam que os ativos intangíveis se tornaram um importante fator de criação de valor na economia do conhecimento de hoje. Entretanto, considerados individualmente, podem ser vistos como commodities e somente criam valor para as firmas quando combinados com outros fatores de produção. Destacam que, no início dos anos 90, ocorreu uma significativa mudança no que se refere à composição dos ativos das corporações. Durante os anos 80, o valor contábil das empresas reduziu-se constantemente em relação ao valor de mercado. Em outras palavras, a diferença entre o valor de mercado e o seu valor contábil, que pode ser considerado como o valor dos ativos intangíveis, apresentou um constante crescimento. Lev e Daum (2004) afirmam que entre 1982 e 1992 o valor dos ativos intangíveis cresceu da proporção de 38 por cento para 62 por cento do valor de mercado das empresas. Investimentos em ativos intangíveis, e em especial aqueles que permitem às empresas inovar, trazem retornos que são significativamente maiores que o custo de capital, até mesmo em indústrias tradicionais. Acrescenta que os sistemas de informações baseados em dados 
contábeis não são mais suficientes para prover aos gestores informações adequadas sobre os ativos das corporações e seu impacto econômico.

Estes pesquisadores argumentam que os ativos intangíveis por si só não criam valor nem geram crescimento, eles precisam ser combinados com fatores de produção. Sem isto, o valor dos intangíveis podem se dissipar mais rápido do que os ativos tangíveis. Destacam que o valor dos ativos intangíveis está relacionado ao futuro e representam capabilities e potencial para crescimento e lucros.

Por outro lado, destacam Lev e Daum (2004), estudos acadêmicos mostram que os investidores sistematicamente atribuem valores incorretos para as ações das empresas intensamente intangíveis. Em geral, empresas inovadoras são excessivamente bem avaliadas, enquanto que para empresas de setores estáveis o inverso é mais frequente: seus intangíveis são subavaliados. Normalmente, os gestores não são capazes de decidir quanto deveriam investir em intangíveis e quais oferecem os melhores retornos. Citam o exemplo dos investimentos em Pesquisa e Desenvolvimento. As empresas não só investem pouco, mas também retiram recursos de inovações de risco que poderiam ser potencialmente lucrativas. Propõem que as empresas deveriam gerar melhores informações sobre seus investimentos em intangíveis e os benefícios que deles resultarão, e então, disponibilizá-las para o mercado de capitais. Desta forma, darão aos investidores uma visão mais clara da empresa e seu desempenho. Isto leva a apreçamentos mais precisos e menor custo de capital.

Allee (2008) argumenta que, para a eficiência do processo de criação de valor, um empreendimento precisa articular a conexão entre a sua estratégia e qual conhecimento é necessário para executá-la. Podemos sintetizar os benefícios econômicos proporcionados pelos ativos intangíveis para as empresas se tivermos em conta o conjunto de direcionadores de valor proposto por Green e Ryan (2005) e da classificação de ativos intangíveis proposta por Kayo et al. (2006). Eles são apresentados no Quadro 1 a seguir.

A partir deste conjunto de direcionadores de valores e tendo como base os objetivos da gestão da gestão do conhecimento para a gestão dos ativos intangíveis propostos por Green e Ryan (2005), pode-se construir uma estrutura dos objetivos da gestão de ativos intangíveis apresentados no Quadro 2.
Lev (2001) destaca que, a partir dos anos 1980, a nova onda direcionada aos ativos intangíveis surgiu da combinação de duas forças econômicas relacionadas: (1) o acirramento da competição nos negócios proporcionado pela globalização e desregulamentação de setores chaves da economia, como telecomunicações, eletricidade, transportes, serviços financeiros; (2) a introdução das tecnologias da informação, destacando-se nesta questão o papel desempenhado pela internet. Estes dois fatores, um político-econômico e outro tecnológico, mudaram consideravelmente a estrutura das corporações e lançaram os intangíveis para um novo patamar como o maior direcionador de valor de negócios nas economias mais desenvolvidas.

Allee (2008) argumenta que uma das mais desafiadoras questões ao tratar-se de intangíveis é como converter ativos como o conhecimento humano, estruturas internas, modo de trabalhar, reputação, relações de negócios, em formas negociáveis de valor. Sugere que o sucesso das empresas ou organizações como um todo depende da eficiência com a qual é capaz de converter uma forma de valor em outra. Cita como exemplo os serviços de consultoria. Nesse caso, esse ativo intangível, um conhecimento especializado de um profissional, é convertido em uma forma mais negociável de valor. Conclui que a chave para a compreensão da economia do conhecimento repousa não somente na compreensão do papel dos ativos intangíveis, mas em como colocá-los em movimento, em configurações únicas de relacionamentos, interações e recursos nas redes de conversão de valor.

Basu e Waymire (2008) tratam os intangíveis como ideias ou conhecimento sobre o mundo natural (físico e biológico) e o sociocultural, que permitem às pessoas atingirem mais facilmente seus objetivos. Incluem pesquisa e evolução da tecnologia, assim como o conhecimento para melhor organizar as trocas e produção e, ao longo do tempo, incorporados em melhores ativos tangíveis. Apresentam o conceito de intangíveis econômicos como o subconjunto de intangíveis culturais capazes de serem usados para criar bens e serviços negociáveis. São cumulativos, sinergéticos, e frequentemente inseparáveis de outros ativos tangíveis e/ou intangíveis econômicos e não detidos por uma entidade única. Assim, argumentam, não há sentido em estimar um valor contábil individualizado para um único ativo intangível. Entretanto, a criação de valor gerada pelo conjunto de intangíveis proporciona insumos úteis para a avaliação do valor da firma. 
Quadro 1 - Direcionadores de valor dos ativos intangíveis

\begin{tabular}{|c|c|c|}
\hline \multicolumn{2}{|c|}{ Direcionador de valor } & \multirow{2}{*}{$\begin{array}{l}\text { Definição } \\
\text { O valor econômico resultante das relações com os clientes (lealdade, satisfação, retenção, } \\
\text { contratos de suprimento, canais de mercado, etc.). }\end{array}$} \\
\hline 1 & Cliente & \\
\hline 2 & Competidor & $\begin{array}{l}\text { O valor econômico resultante da posição ocupada no mercado (reputação, marketshare, } \\
\text { reconhecimento do nome, imagem, etc.). }\end{array}$ \\
\hline 3 & Empregados & $\begin{array}{l}\text { O valor econômico resultante das capabilities coletivas dos empregados (conhecimento, habi- } \\
\text { lidade, competência, know-how, talento, capacidade administrativa, retenção de colaborado- } \\
\text { res-chaves, treinamento e desenvolvimento, etc.). }\end{array}$ \\
\hline 4 & Informação & $\begin{array}{l}\text { O valor econômico resultante da habilidade de recolher e disseminar informações e conheci- } \\
\text { mento na forma e conteúdo corretos, para as pessoas certas, no tempo certo. }\end{array}$ \\
\hline 5 & Parceria/Redes & $\begin{array}{l}\text { O valor econômico resultante das associações (financeiras, estratégicas, de autoridade, força, } \\
\text { etc.) estabelecidas com indivíduos e organizações externas (consultores, clientes, fornecedo- } \\
\text { res, aliados, competidores, etc.). }\end{array}$ \\
\hline 6 & Rotinas & $\begin{array}{l}\text { O valor econômico resultante da habilidade do empreendimento para alavancar as formas } \\
\text { pelas quais opera o empreendimento e cria valor (políticas, procedimentos, metodologias, } \\
\text { técnicas, etc.). }\end{array}$ \\
\hline 7 & Produto/Serviço & $\begin{array}{l}\text { O valor econômico resultante da habilidade para desenvolver e disponibilizar suas ofertas } \\
\text { (produtos e serviços) e que refletem uma compreensão sobre o mercado e requisitos, desejos } \\
\text { e expectativas dos clientes. }\end{array}$ \\
\hline 8 & Tecnologia & $\begin{array}{l}\text { O valor econômico resultante da tecnologia empregada para suportar as operações com } \\
\text { eficiência e diferenciais estratégicos. }\end{array}$ \\
\hline
\end{tabular}

Fonte: Elaborado pelos autores a partir de GREEN; RYAN, 2005, p. 47.

Tendo esta argumentação como fundamento, Basu e Waymire (2008) colocam-se contrários a qualquer incorporação de ativos intangíveis nos demonstrativos contábeis, já que não podem ter seu valor reconhecido individualmente, ao contrário dos ativos tangíveis. Argumentam que, embora tenham se destacado nas últimas décadas, ativos intangíveis estão presentes em todas as interações econômicas, até mesmo nas mais simples. Além disso, ativos intangíveis são ideias construídas a partir de outras ideias, gerando complementaridade e sinergias. Como exemplo, teríamos as vantagens competitivas geradas pela parceria de duas empresas criando valor para ambas. Como consequência, o valor de uma ideia individual não pode ser discernido de forma independente de outras ideias, muitas das quais não são detidas por uma firma, vista de forma isolada. E mais do que isto, intangíveis só trariam vantagens competitivas sustentáveis na medida em que eles criem valor, ou utilizando-se uma expressão contábil, que gerem receitas.

Esta argumentação, segundo Basu e Waymire (2008), não contradiz, porém, que ideias culturais possam ser convertidas em bens valiosos, serviços e eventualmente direitos protegidos de propriedade e, por isto, possam ser contabilizados e, assim, possam ser considerados ativos intangíveis contabilizáveis. Contudo, encontram-se poucas ideias que possam ganhar o status de propriedades privadas, até mesmo em economias desenvolvidas. Há que se destacar também que seria possível subavaliar os ativos intangíveis nos demonstrativos contábeis. Desta forma, estariam sinalizando robustez econômica, na medida em que os retornos sobre seus patrimônios líquidos seriam elevados, em uma aparente demonstração de uma alta capacidade de gestão de seus recursos tangíveis. Os autores argumentam que mesmo ativos intangíveis contabilizáveis não podem ser separados de outros ativos intangíveis incorporados no aprimoramento de bens tangíveis e serviços. De forma similar, muitos ativos intangíveis serão incorporados em futuros ativos tangíveis. Concluem que ativos intangíveis só são economicamente valiosos se forem capazes de gerar riquezas para quem os utiliza, o que implica que o valor dos ativos intangíveis deriva das receitas que eles produzem. 
Quadro 2 - Objetivos da gestão dos ativos intangíveis

\begin{tabular}{ll}
\hline Objetivo & Descrição \\
\hline Inovação & $\begin{array}{l}\text { Gerar novas ideias para o desenvolvimento de novos produtos, de novos serviços, de habilida- } \\
\text { des avançadas e de melhores práticas. } \\
\text { Erganização }\end{array}$ \\
$\begin{array}{l}\text { Estruturar recursos para aprimorar a captura, transferência e o compartilhamento do conhe- } \\
\text { cimento. }\end{array}$ \\
Estabelecer interações entre recursos para aprimorar a captura, transferência e o compartilha- \\
mento do conhecimento. \\
Estabelecer um ambiente de visões e valores que aprimore a colaboração, a criatividade, a \\
comunicação, a confiança e o compartilhamento de conhecimento.
\end{tabular}

Fonte: Elaborado pelos autores a partir de GREEN; RYAN, 2005, p. 49.

Danthine e Jin (2007) lembram que estudos recentes demonstram que o capital intangível não mensurado é amplo e importante e que, por natureza, a acumulação do capital intangível é bem diferente da acumulação do capital físico. É possível, segundo os pesquisadores, assumir-se que investimentos em intangíveis resultam estocasticamente em capital físico. Kohlbeck e Warfield (2007) demonstram que ativos intangíveis não contabilizados estão relacionados a ganhos anormais e valorização do patrimônio tangível de forma persistente.

Sriram (2008) argumenta que as firmas da moderna economia criam e usam ativos intangíveis com $v a$ lores percebidos. Isto não significa que a longo prazo estejam assegurados o crescimento e a sobrevivência da empresa. Para isto, é necessário que as firmas possam garantir o suprimento de capitais originados a partir de seus investidores para sustentar a criação de ativos intangíveis que gerem vendas e lucros futuros. Criar ativos intelectuais e eventualmente usá-los para resultar em vendas e lucros pode tomar muito tempo, algumas vezes anos. Durante este longo período de gestação, os investidores devem manter a confiança nos gestores e na sua habilidade de criar e obter valor a partir dos ativos intelectuais. Portanto, conclui o autor, a prova final do valor dos ativos intelectuais é demonstrada pelos indicadores de desempenho fundamentais como vendas, lucro líquido a retorno sobre o patrimônio. Se estes retornos tangíveis não são significativos, os investidores recuarão e não suprirão o capital necessário para suportar as operações destas empresas. A história recente das firmas voltadas para a internet oferece amplas evidências do inter-relacionamento entre ativos intangíveis e desempenho financeiro fundamental esperado. É por esta razão que a análise de variáveis financeiras fundamentais, que são objetivamente mensuradas e publicadas em demonstrativos contábeis, é ainda muito importante quando se avalia a saúde financeira da firma, independente da sua composição de ativos ou do seu modelo de negócios. Os indicadores financeiros fundamentais não devem ser ignorados, destaca este pesquisador.

\section{Valor de mercado das firmas e risco}

O valor de mercado só pode ser apurado para firmas que estão constantemente sendo negociadas, portanto, firmas de capital aberto, com suas ações sendo negociadas em bolsa. A Hipótese da Eficiência de Mercado é um dos pilares da moderna teoria de finanças e tem como premissa que, em mercados eficientes, os preços dos ativos refletem instantaneamente todas as informações relevantes disponíveis no mercado e que afetariam os retornos obtidos pelos investidores (FAMA, 1970). Para Brealey e Myers (2003), segundo a teoria tradicional de valoração de ativos, o valor de mercado das empresas é obtido a partir da soma de dois componentes: o primeiro representado pelo valor presente líquido da expectativa dos fluxos de caixa futuros gerados pela firma a partir dos seus ativos e das suas operações atuais, e o segundo componente como o valor presente líquido da expectativa de fluxos de caixa futuros gerados a partir das oportunidades de crescimento disponíveis e que podem ser aproveitados pela empresa. Entendem-se como oportunidades de crescimento 
aos projetos selecionados pelos gestores das empresas, como alianças estratégicas e evolução dos mercados em que atuam. Deste modo, os preços das ações contêm as expectativas dos investidores em relação à lucratividade e ao desempenho futuro das firmas, já que utilizam estas informações para a formação dos preços.

Sob a luz da teoria da eficiência de mercado, o valor de mercado das empresas que têm suas ações negociadas no mercado de capitais representa o valor intrínseco de seus ativos, portanto, a soma do valor dos seus ativos tangíveis e intangíveis. Nos demonstrativos contábeis encontram-se o valor dos seus ativos tangíveis mais uma parcela do valor dos ativos intangíveis para os quais exista um mercado ativo, e, desta forma, possam ser atribuídos valores contábeis. Assim, a diferença entre o valor de mercado e o valor de seus ativos tangíveis representa o valor do seu intangível não contabilizado. Sob a Hipótese de Mercados Eficientes, podemos concluir que este resultado é equivalente ao valor intrínseco dos ativos intangíveis idiossincráticos das empresas.

Entretanto, é preciso fazer algumas considerações sobre o valor de mercado das firmas. 0 valor de mercado das empresas que têm suas ações cotadas em bolsa é influenciado pelo risco do retorno. Um dos temas mais discutidos e pesquisados em finanças corporativas tem sido a determinação das taxas de retorno que são exigidas nos investimentos. A taxa de retorno é elemento fundamental para a alocação de recursos e a análise de risco-retorno. O modelo CAPM - Capital Asset Pricing Model - tem sido amplamente utilizado desde sua formulação por Willian Sharpe na década de 1960 para determinação da taxa de retorno esperada dos ativos. o CAPM estabelece que, considerando a premissa que os investidores são racionais e trabalham buscando a melhor opção de investimento, os mesmos diversificam seus investimentos a fim de evitarem o risco não sistemático (inerente às empresas e ativos individuais), exigindo retorno adicional apenas pelo risco sistemático (SHARPE, 1964). Entende-se risco sistemático como a parcela do risco total não eliminado por meio de uma estratégia de diversificação. Quanto maior o risco percebido de um ativo, maior será o retorno requerido pelos investidores racionais para assumir este risco. Brealey e Myers (2003) descrevem o risco do investimento como a imprevisibilidade dos retornos futuros.
A ideia fundamental por trás do modelo de apreçamento CAPM é que o prêmio de risco esperado de cada título deve aumentar na proporção do seu Beta (prêmio de risco esperado $=$ Beta $x$ prêmio de risco de mercado). 0 coeficiente Beta é definido como a medida do risco sistemático, que demonstra a tendência pela qual o retorno de um ativo se move em paralelo com o retorno do mercado de capitais como um todo, ou ainda a volatilidade do ativo comparada à do mercado.

Portanto, o valor dos ativos intangíveis tem forte influência do risco percebido pelo mercado e assim condicionar o prêmio de risco esperado pelos investidores, afetando significativamente a atribuição de preço pelo mercado. Como não há um mercado para os ativos intangíveis idiossincráticos das empresas, sua avaliação se torna mais complexa, pois o fluxo de caixa que proporcionarão é mais incerto, ou em termos financeiros, de maior risco. Desta forma, é natural que os investidores, diante de um risco maior, irão requerer um maior prêmio de risco.

A relação entre os conceitos de recursos estratégicos e ativos intangíveis

Conforme destacado nos itens anteriores, procurou-se definir sob a luz dos autores e trabalhos seminais apresentados, a existência de uma forte relação entre os conceitos de recursos estratégicos, notadamente os de natureza humana e/ou organizacional, discutidos no campo da estratégia de empresas, e ativos intangíveis, objeto de discussão em finanças corporativas.

Por meio desta discussão entende-se que existe uma correspondência muito forte entre os dois constructos, na medida em que se entende que recursos humanos, organizacionais e ativos intangíveis são sinônimos no ambiente empresarial, levando a especular sobre terem esses constructos uma mesma origem enquanto fonte de geração de valor nas empresas.

Este trabalho procura mostrar que a percepção do mercado sobre o valor intangível das empresas, presente no apreçamento que o mercado faz ao negociar as suas ações no mercado de capitais, representa uma mensuração possível dos chamados recursos estratégicos não físicos, devido à correspondência que se procura demonstrar.

Nesse sentido, entende-se que esse preço adicional originado pelos investidores na negociação 
dos ativos da empresa atua como uma fonte de recursos financeiros que irá alimentar a empresa na implementação de novas estratégias voltadas a VCS, buscando sempre aumentar a riqueza da firma, e por consequência dos seus acionistas.

A Figura 1 representa o processo de retroalimentação dos investimentos em ativos intangíveis gerando novas rendas que serão aplicadas em novas estratégias, mantendo o círculo virtuoso do processo.

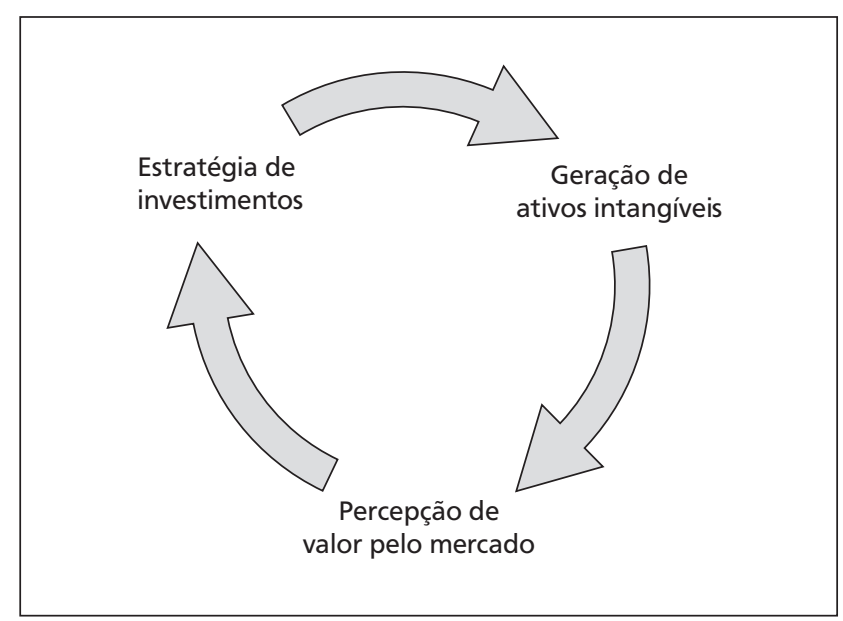

Figura 1 - Retroalimentação de investimentos Fonte: Dados da pesquisa.

\section{Considerações finais}

Com este estudo se procurou mostrar que as estratégias utilizadas por investidores no mercado financeiro, ao terem em conta o índice obtido entre o valor de mercado da empresa e seu valor contábil, são coerentes com as abordagens baseadas em recursos. 0 objetivo dos recursos estratégicos é agregar valor para os bens e serviços de tal forma que possam ser transacionados com valor adicional, proporcionando sua transformação em resultados financeiros para as empresas.

Os ativos tangíveis das empresas são transacionados em mercados de fatores, assim como os ativos intangíveis para os quais há um mercado ativo para eles. Sendo assim, segundo a RBV, não poderiam se tornar fontes de vantagens competitivas sustentáveis, pois todas as empresas teriam igual acesso a eles nas economias abertas. Ao contrário, os ativos idiossincráticos das empresas, ou os ativos intangíveis não contabilizáveis por não haver um mercado ativo para eles, seriam os responsáveis pelo desempenho financeiro superior destas empresas.
Foram apresentadas diversas pesquisas que demonstram a existência desse valor intrínseco presente no "valor da firma", explicitado ao se calcular o montante representado pelo preço dos ativos das empresas no mercado de capitais multiplicado pela quantidade disponível para transação (capital emitido), e comparando-o com o valor do Patrimônio Líquido apontado no Balanço Patrimonial das empresas.

Foi identificado que é possível utilizar esse valor intrínseco como uma proxy para valoração dos recursos estratégicos não físicos das empresas, e assim contribuir para os estudos no campo da estratégia de empresas, à medida que possibilita valorá-los. É possível, dessa forma, medir a contribuição desses recursos estratégicos para os seus resultados e consequentemente para o seu valor.

Com o presente artigo não se tem, entretanto, a pretensão de solucionar a questão colocada nos meios acadêmicos quando busca atribuir valor aos recursos estratégicos das empresas. Reconhece-se que diversas outras pesquisas neste sentido vêm sendo elaborados pela comunidade acadêmica e que podem chegar a conclusões bastante diversas do que esta. Busca-se, sim, estimular novas pesquisas para que outros constructos a respeito da forma de mensuração de recursos estratégicos não físicos sejam elaborados e discutidos, em especial para as pesquisas que pretendem individualizar o valor destes recursos.

\section{Referências}

ALLEE, V. Value network analysis and value conversion of tangible and intangible assets. Journal of Intellectual Capital, v. 9, n. 1, p. 5-24, 2008.

AMIT, R.; SCHOEMAKER, P. J. H. Strategic assets and organizational rent. Strategic Management Journal, v. 14, n. 1, p. 33-46, 1993.

BARNEY, J. B. Strategic factor markets: expectations, luck, and business strategy. Management Science, v. 32, n. 10, p. 1231-1241, 1986.

BARNEY, J. B. Firm resources and sustained competitive advantage. Journal of Management, v. 17, n. 1, p. 99-120, 1991.

BARNEY, J. B. Is the resource-based "view" a useful perspective for strategic management research? Yes. Academy of Management Review, v. 26, n. 1, p. 41-56, 2001. 
BASU, S.; WAYMIRE, G. Has the importance of intangibles really grown? And if so, why? Accounting and Business Research, v. 38. n. 3, p. 171-190, 2008.

BREALEY, R. A.; MYERS, S. C. Principles of corporate finance. Boston: McGraw-Hill, 2003.

DANTHINE, J. P.; JIN, X. Intangible capital, corporate valuation and asset pricing. Economic Theory, v. 32, n. 1, p. 157-177, 2007.

FAMA, E. F. Efficient capital markets: a review of theory and empirical work. Journal of Finance, v. 25, n. 2, p. 383-418, 1970.

GREEN, A.; RYAN, J. C. H. A framework of intangible valuation areas (FIVA): aligning business strategy and intangible assets. Journal of Intellectual Capital, v. 6, n. 1, p. 43-52, 2005.

HALL, R. A framework linking intangible resources and capabilites to sustainable competitive advantage. Strategic Management Journal, v. 14, n. 8, p. 607-618, 1993.

KAYO, E. K. et al. Ativos intangíveis, ciclo de vida e criação de valor. Revista de Administração Contemporânea, v. 10, n. 3 , p. 73-93, 2006.

KOHLBECK, M.; WARFIELD, T. D. Unrecorded intangible assets: abnormal earnings and valuation. Accounting Horizons, v. 21, n. 1, p. 23-41, 2007.

LEV, B. Intangibles: management, measurement and reporting. Washington, D.C.: Brookings Institution Press, 2001.

LEV, B.; DAUM, J. H. The dominance of intangible assets: consequences for enterprise management and corporate reporting. Measuring Business Excellence, v. 8, n. 1, p. 6-17, 2004.

PENROSE, E. The theory of the growth of the firm. New York: Wiley, 1959.

PETERAF, M. The cornerstones of competitive advantage: a resource-based view. Strategic Management Journal, v. 14, n. 3, p. 179-191, 1993.

PORTER, M. Competitive strategy: techniques for analyzing industries and competitors. New York: Free Press, 1980.
PORTER, M. Competitive advantage. New York: Free Press, 1985.

PRAHALAD, C. K.; HAMEL, G. Strategy as a field of study: why search for a new paradigm? Strategic Management Journal, v. 15, p. 5-16, 1994.

SHARPE, W. F. Capital asset prices: a theory of market equilibrium under conditions of risk. The Journal of Finance, v. 19, n. 3, p. 425-442, 1964.

SHARPE, W. F.; ALEXANDER, G. J.; BAILEY, J. V. Investments. New Jersey: Prentice Hall, 1995.

SRIRAM, R. S. Relevance of intangible assets to evaluate financial health. Journal of Intellectual Capital, v. 9, n. 3, p. 351-366, 2008.

STEWART, T. A. The wealth of knowledge: intellectual capital and the twenty-first century organization. New York: Currency, 2001.

SULLIVAN JUNIOR, P. H. Valuing intangibles companies: an intellectual capital approach. Journal of Intellectual Capital, v. 1, n. 4, p. 328-340, 2000.

SVEIBY, K. E. A nova riqueza das organizações. Gerenciando e avaliando patrimônios de conhecimento. Rio de Janeiro: Campus, 1998.

WERNERFELT, B. A resource-based view of the firm. Strategic Management Journal, v. 5, n. 2, p. 171-180, 1984.

Recebido: 05/09/2011

Received: 09/05/2011

Aprovado: 11/10/2011

Approved: 10/11/2011 